Original Research Paper

\title{
Access to and Uptake of Contraception by Women with Disabilities
}

\author{
Natal Ayiga and Stella Kigozi \\ Population Research and Training Unit, \\ North West University Mafikeng Campus, Private bag X2046 Mmabatho, 2735, South Africa
}

\section{Article history}

Received: 23-05-2016

Revised: $14-11-2016$

Accepted: 22-11-2016

Corresponding Author:

Natal Ayiga

Population Research and

Training Unit, North West

University Mafikeng Campus,

Private bag X2046 Mmabatho,

2735, South Africa

Email: Natal.Ayiga@nwu.ac.za nayiga1962@gmail.com

\begin{abstract}
Contraception has been identified as an imperative for achieving the Sustainable Development Goals. In poor countries, the need for contraception is highest among the most vulnerable population groups. One such group is women with disabilities. The objectives of this study were to examine uptake of and identify the predictors of use of contraception by women in Uganda with disabilities. The study used cross-sectional data on 1128 sexually experienced women in the 15-49 year age group with disabilities. The data were obtained from the 2011 Uganda Demographic and Health Survey. The binary logistic regression model was used to analyse the data. The study found that only $26.1 \%$ of the women had ever used contraception and the results confirmed the hypothesis that access to health facilities and access to family planning information on radio significantly increased uptake of contraception. Other factors that significantly increased uptake of contraception were attending 4 or more Antenatal Care (ANC) visits, being in the 25-34 year age group, living in Kampala region, having primary, secondary or higher education, being in the middle or richer wealth index groups and having almost daily access to radio. We conclude that uptake of contraception by women with disabilities is low and reflects the high unmet need for contraception for women in Uganda, which could be explained by the pervasive structural inequalities in access to contraception services.
\end{abstract}

Keywords: Family Planning, Maternal Health, Disability, Media

\section{Introduction}

Access to and uptake of contraception is important for achieving the recently launched Sustainable Development Goals (SDGs). Contraception can contribute to reducing chronic poverty and hunger, increasing access to quality education, enhancing gender equality, improving maternal health and reducing childhood mortality through its role in preventing unwanted pregnancy and reducing fertility rate (Cates Jr, 2010). It can also contribute to the sustainable use of environmental resources, reduce the pace of climate change (Haq et al., 2010) and the frequency and severity of conflicts around the world (Galati, 2015) by reducing the level of competition for resources induced by population growth (Ujoh, 2014).

In poor countries, the need for contraception is greatest among population groups at the highest risk of health and socioeconomic vulnerabilities because of their reduced capacity to cope, respond to and counter livelihood shocks. One such group is women with disabilities. Disability has been defined in various ways, but generally refers to any condition that prevents a person from living a normal social and working life. It is characterized by impairment in body functions; limitations in executing tasks; and restrictions in involvement in life situations (WHO, 2011). Disabilities can take several dimensions including physical, cognitive, mental and developmental, or a combination of two or more of these. It can occur at birth or be acquired at any stage during the life course (Low and Pistaferri, 2010). Disability is also a manifestation of the interaction between a person and features of the society in which he/she lives (Tuomilehto and Wareham, 2002).

Irrespective of the form or stage at which a disability occurs, it is a serious cause of exclusion of people directly affected by it and/or their families not only because it carries negative and derogative connotations in many societies, but also because it can significantly affect individual and family economic and social functions for a long time. For example, among the Shona of Zimbabwe, disability was regarded as a state of being less human (Charlton, 2000); in some societies in Asia, 
having a disability was regarded as a punishment from God for sins committed by the individual with a disability or his/her parent(s) (Eisland, 1994); and in Uganda it was regarded as a curse locally known as "Kisirani" (Lwanga-Ntale, 2003). Economically and socially, many individuals with disabilities and their families are poorer and often excluded from vital services because disability affects their finances, career, opportunities, how they allocation their time as well as their health (Chakravarti, 2008; Richard, 2014). As a result, persons with disabilities have various vulnerabilities. For example, they have poorer access to health, education, economic opportunities and often live in poverty. The lower income countries, mostly in subSaharan Africa, have a higher burden and impact of disabilities from various causes than anywhere else in the world. In these countries women are disproportionately more affected than men by disabilities and their impacts (Mitra et al., 2013; Naami, 2015).

\section{Disabilities and Reproductive Health Services}

Disability is one of the major obstacles to uptake of reproductive health services in sub-Saharan Africa because persons having disabilities are perceived to be asexual and unlikely to marry or bear children (Ahumuza et al., 2014; Ganle et al., 2016; Lang, 2009). One of the least used reproductive health care services by women with disabilities in these societies is contraception (Ganle et al., 2016; Kaplan, 2006). This situation is attributed to the structural barriers of poor access to health facilities in rural areas where most women with disabilities live and systemic barriers exacerbated by the poor attitude of health workers to the reproductive health needs of women with disabilities (Barriga and Kwon, 2010; Hamid and Stephenson, 2006). Pervasive discrimination against women with disabilities in matters related to sexuality, fuelled by the perception that they do not need contraception because they are asexual (Ahumuza et al., 2014) and their inadequate knowledge contributes to the low uptake of reproductive health services (Thomas, 2004; Trani et al., 2011). Despite having a national policy on disability and the Persons with Disabilities Act, many women in Uganda with disabilities face many barriers in accessing reproductive health services including contraception (Thomas, 2004). As a result, the unmet need for family planning, which is the number of women who would like to space, limit or stop childbearing, but lack access to methods for doing so, is high among women with disabilities (Ahumuza et al., 2014).

\section{Problem Statement}

The literature from developed countries shows that there has been significant progress in addressing the reproductive health needs of women with disabilities (Leigh et al., 2004; WHO, 2011). However, there is a paucity of knowledge on the reproductive health of women with disabilities in low income countries, especially those in sub-Saharan Africa where the burden of disability is high. The few small area studies on the reproductive health of women with disabilities in subSaharan Africa suggest that compared to normal women, women with disabilities are neglected and excluded from contraception (Ahumuza et al., 2014; Ganle et al., 2016). As a result, they remain at high risk of unwanted and mistimed pregnancies and are exposed to health and socioeconomic vulnerabilities associated with childbearing as they cannot cope or respond effectively to the limitations and incapacities imposed on them by disability. We are also not aware of any studies using nationally representative data on disabilities and contraception in Uganda that examined the barriers faced by women with disabilities in using contraception. As a result the predisposing and enabling factors that affect the uptake of contraception by women with disabilities in Uganda have remained unknown. The objectives of the study were therefore to assess the national prevalence of and identify the predictors of uptake of contraception in Uganda by women with disabilities.

The study used the Andersen's Behavioural Model for Health Services Use (Babitsch et al., 2012) to identify predictors of uptake of contraception by women with disabilities. We propose that uptake of contraception is influenced by the combination of predisposing, enabling and needs factors. The predisposing factors operate at an individual level to influence the need for contraception and they include age, marital status and education. Enabling factors are those that facilitate uptake of contraception including access to health facilities, access to family planning information, wealth status of women, place and region of residence and husband's level of education. Factors that influence the need for contraception included in the study were knowledge of contraception, number of surviving children, fertility intentions of women and husband's/partner's number of children desired.

\section{Materials and Methods}

\section{Data and Sample}

The study used cross-sectional data on 8740 women within the reproductive ages of 15-49. The data were obtained from the Uganda Demographic and Health Survey (UDHS), which was conducted by the Uganda Bureau of Statistics (UBOS) and ICF International in 2011. The survey collected data on demographic, socioeconomic, reproduction, contraception, sexual and reproductive health, nutrition, HIV and AIDS and gender based violence characteristics of the women.

The sample for the survey was nationally representative and was drawn by the use of a two stage cluster sampling design. In the first stage 404 enumeration areas distributed all over Uganda (EAs) were selected as clusters from a sample frame developed from the 2002 
Uganda population and household census. The second stage comprised the selection of 10086 households from the selected EAs. From the households, all women aged 15-49 years who resided in the households and those who visited and stayed the preceding night in the household were interviewed. The interviews were conducted by trained research assistants with previous research experience using the face to face method. A standard and structured woman's questionnaire designed by the Measure DHS programme to collect data from 91 developing countries was used to collect the data from the women. The questionnaire used to collect the data was translated from English to the local languages in the different regions.

Disability status and ever given birth were the eligibility criteria for inclusion of the women in the study. In this regard women with any form of disability including any condition which moderately, severely or completely impaired sight, hearing, walking, remembering or communication, or two or more of the above conditions were included in the study. To ensure robustness of the sample, an aggregate variable called disability status was created. This variable had two categories, namely having disabilities and having no disabilities. The category having disabilities was then used to select the 1128 records analysed.

Ethical approval for the study was obtained from the Institutional Review Board of UBOS. Before collecting data, informed consent was obtained from respondents after explaining to them the purpose and objectives of the survey. The respondents were also informed of their right to withdraw from the survey or decline answering questions they were not comfortable with. Interviews were conducted in private, confidentially and anonymously. Permission to use the data in this study was obtained from UBOS.

\section{The Dependent and Independent Variables}

In this study, the dependent variable was uptake of contraception, which included ever use of any hormonal, surgical or barrier methods for the purpose of regulating fertility. A woman with a disability who reported ever using any of the above methods was regarded as having used contraception. The independent variables comprised of predisposing, enabling and contraceptive needs variables. The predisposing variables included age groups categorized as $<25,25-34$ and 35 years or older; level of education categorized as uneducated, primary, secondary or tertiary education. Another predisposing variable was marital status categorized as never married, currently married or formerly married (separated, divorced and widowed).

The enabling variables comprise some individual, community and husband's level variables that could facilitate uptake of contraception. These include access to health services categorized as with difficult or without difficulty; access to radio categorized as occasional or almost daily; access to family planning messages on radio categorized as yes or no; and wealth index group categorized as poorer, middle or richer. Also included as enabling variables are place of residence categorized as rural or urban and region of residence categorized as Kampala, Central, Eastern, Northern or Western regions. Antenatal care attendance during the last pregnancy categorized as $<4$ or 4 or more times; husband's education level categorized as uneducated or primary, secondary or tertiary and unknown; and husband's ideal number of children desired categorized as same as spouse, more than spouse, fewer than spouse or not known were also included as enabling variables. The contraception need variables were those that influence women's demand for contraception. These included knowledge of contraceptives categorized as yes or no; number of surviving children categorized as " $<4$ ", " 4 " or more; and fertility intentions of the women categorized as want another child, undecided or want no more children.

\section{Methods of Analysis}

The statistical analysis was done in three stages. In the first stage, we described the profile of the women by the selected variables. At this level of analysis, frequency distributions of all variables were employed to describe the profile of the women. At the second stage, we used the chi-square statistics of the form $x^{2}=\sum_{i=1}^{i} \frac{\left(O_{i j}-E_{i j}\right)^{2}}{E_{i j}}$ to examine the association between the predisposing, enabling and need variables and uptake of contraception. We concluded that a significant association existed if the $\mathrm{p}<0.05$.

At the third stage, which was the multivariate analysis, the binary logistic regression model was used because the structure of the dependent variable was dichotomous in which uptake of contraception was coded " 1 " and " 0 " if otherwise. The model was chosen because the dependent variable met the conditions for the use of the model (Elisa and Wang, 2003). The logistic regression model used was of the form: $y=\log _{e} \frac{P_{i}}{1-P_{I}}$. The estimator used to interpret the results was the exponentiated beta-coefficients $\left(\beta^{\mathrm{x}}\right)$ (Odds Ratio). We concluded that a variable was a significant predictor of uptake of contraception if the $p$ value associated with the Odds Ratio was $<0.05$.

\section{Results}

The socio-demographic profile of the women is presented in Table 1 showing that the median age of the women was 33 years and the majority were in the 35 years or older age group. The mean number of surviving children was 4.2 and nearly 7 in 10 of the women had at least 4 children which is an indication of high fertility. 
Table 1. Percentage distribution of women with disabilities by selected characteristics

\begin{tabular}{|c|c|c|}
\hline \multirow{2}{*}{\multicolumn{3}{|c|}{$\frac{\text { Characteristics }}{\text { Age group }}$}} \\
\hline & & \\
\hline$<25$ & 21.1 & 238 \\
\hline $25-34$ & 32 & 361 \\
\hline $35+$ & 46.9 & 529 \\
\hline Median age & 33 & \\
\hline \multicolumn{3}{|l|}{ Number of children surviving } \\
\hline$<4$ & 43.4 & 489 \\
\hline $4+$ & 56.6 & 639 \\
\hline Mean number of children surviving & 4.2 & \\
\hline \multicolumn{3}{|l|}{ Fertility intentions } \\
\hline Want another child & 42.1 & 475 \\
\hline Undecided & 2.4 & 27 \\
\hline Want no more children & 55.5 & 626 \\
\hline \multicolumn{3}{|l|}{ Place of residence } \\
\hline Urban & 24.1 & 272 \\
\hline Rural & 75.9 & 856 \\
\hline \multicolumn{3}{|l|}{ Level of education } \\
\hline Uneducated & 17.5 & 197 \\
\hline Primary & 60.8 & 686 \\
\hline Secondary & 17.1 & 193 \\
\hline Tertiary & 4.6 & 52 \\
\hline \multicolumn{3}{|l|}{ Religious affiliation } \\
\hline Catholic & 43.9 & 495 \\
\hline Other Christians & 43.6 & 492 \\
\hline Muslims & 10.9 & 123 \\
\hline Others & 1.6 & 18 \\
\hline \multicolumn{3}{|l|}{ Marital status } \\
\hline Never in union & 8.8 & 99 \\
\hline Currently in union & 70.2 & 792 \\
\hline Formerly in Union & 21 & 237 \\
\hline \multicolumn{3}{|l|}{ Region of residence } \\
\hline Kampala & 7.8 & 88 \\
\hline Central & 22.6 & 255 \\
\hline Eastern & 26.2 & 295 \\
\hline Northern & 17 & 192 \\
\hline Western & 26.4 & 298 \\
\hline \multicolumn{3}{|l|}{ Wealth status } \\
\hline Poorer & 38.5 & 434 \\
\hline Middle & 18.9 & 213 \\
\hline Richer & 42.6 & 481 \\
\hline \multicolumn{3}{|l|}{ Access to the radio } \\
\hline Occasional & 43.3 & 488 \\
\hline Almost daily & 56.7 & 640 \\
\hline \multicolumn{3}{|c|}{ Knowledge of modern family planning methods } \\
\hline No & 0.5 & 6 \\
\hline Yes & 99.5 & 1122 \\
\hline \multicolumn{3}{|c|}{ Ever received family planning messages on radio } \\
\hline No & 28.5 & 321 \\
\hline Yes & 71.5 & 807 \\
\hline \multicolumn{3}{|l|}{ Access to health facility } \\
\hline With difficulty & 73.8 & 832 \\
\hline Without difficulty & 26.2 & 296 \\
\hline Number of ANC visits during last $\mathrm{p}$ & & \\
\hline$<4$ & 74.1 & 836 \\
\hline 4 or more & 25.9 & 292 \\
\hline Ever used contraceptives & & \\
\hline Yes & 26.1 & 294 \\
\hline No & 73.9 & 834 \\
\hline Husband's education level & & \\
\hline Uneducated or primary & 57.5 & 624 \\
\hline Secondary or tertiary & 30.7 & 333 \\
\hline Unknown & 11.9 & 129 \\
\hline Husband's number of children desir & & \\
\hline Same as spouse & 18.6 & 210 \\
\hline More than spouse & 23.6 & 266 \\
\hline Fewer than spouse & 5.6 & 63 \\
\hline Don't know & 52.2 & 589 \\
\hline Total & 100 & 1128 \\
\hline
\end{tabular}


Natal Ayiga and Stella Kigozi / Journal of Social Sciences 2016, 12 (4): 171.181 DOI: $10.3844 / j s s p .2016 .171 .181$

Table 2. Differentials in uptake of contraceptives by selected characteristics

\begin{tabular}{|c|c|c|c|c|}
\hline \multirow[b]{2}{*}{ Characteristics of women } & \multicolumn{2}{|c|}{ Uptake of contraception } & \multirow[b]{2}{*}{ Number } & \multirow[b]{2}{*}{$X^{2}$} \\
\hline & Never used & Ever used & & \\
\hline \multicolumn{5}{|l|}{ Age group } \\
\hline$<25$ & 76.9 & 23.1 & 238 & \multirow[t]{3}{*}{$10.15, p=0.006$} \\
\hline $25-34$ & 67.9 & 32.1 & 361 & \\
\hline $35+$ & 76.7 & 23 & 529 & \\
\hline \multicolumn{5}{|c|}{ Number of surviving children } \\
\hline$<4$ & 73.6 & 26.4 & 489 & \multirow[t]{2}{*}{$0.04, p=0.442$} \\
\hline $4+$ & 74.2 & 25.8 & 639 & \\
\hline \multicolumn{5}{|l|}{ Fertility intentions } \\
\hline Want another child & 74.3 & 25.7 & 475 & \multirow[t]{3}{*}{$2.00, p=0.367$} \\
\hline Undecided & 85.2 & 14.8 & 27 & \\
\hline Want no more children & 73.2 & 26.86 & 626 & \\
\hline \multicolumn{5}{|l|}{ Place of residence } \\
\hline Urban & 66.2 & 33.8 & 272 & \multirow{2}{*}{$11.20, p=0.001$} \\
\hline Rural & 76.4 & 23.6 & 856 & \\
\hline \multicolumn{5}{|l|}{ Level of education } \\
\hline Uneducated & 87.8 & 12.2 & 197 & \multirow[t]{4}{*}{$33.68, \mathrm{p}=0.0001$} \\
\hline Primary & 73.6 & 26.4 & 686 & \\
\hline Secondary & 64.8 & 35.2 & 193 & \\
\hline Tertiary & 59.6 & 40.4 & 52 & \\
\hline \multicolumn{5}{|l|}{ Religious affiliation } \\
\hline Catholic Christians & 76.2 & 23.8 & 495 & \multirow[t]{4}{*}{$4.99, p=0.172$} \\
\hline Other Christians & 73 & 27 & 492 & \\
\hline Muslims & 67.5 & 32.5 & 123 & \\
\hline Others & 83.3 & 16.7 & 18 & \\
\hline Marital status & & & & \\
\hline Never in union & 78.8 & 21.2 & 99 & $4.69, p=0.096$ \\
\hline Currently in union & 72.1 & 27.9 & 792 & \\
\hline Formerly in Union & 78.1 & 21.9 & 237 & \\
\hline Region of residence & & & & \\
\hline Kampala & 69.3 & 30.7 & 88 & $10.77, p=0.029$ \\
\hline Central & 68.6 & 31.4 & 255 & \\
\hline Eastern & 72.2 & 27.8 & 295 & \\
\hline Northern & 77.6 & 22.4 & 192 & \\
\hline Western & 79.2 & 20.8 & 298 & \\
\hline Wealth status & & & & \\
\hline Poorer & 83.9 & 16.1 & 434 & $39.47, p=0.000$ \\
\hline Middle & 72.3 & 27.7 & 213 & \\
\hline Richer & 65.7 & 34.3 & 481 & \\
\hline Access to the Radio & & & & \\
\hline Occasional & 79.3 & 20.7 & 488 & $12.85, \mathrm{p}=0.000$ \\
\hline Almost daily & 69.8 & 30.2 & 640 & \\
\hline Ever received family plan & & & & \\
\hline No & 81.9 & 18.1 & 321 & $14.88, p=0.000$ \\
\hline Yes & 70.8 & 29.2 & 807 & \\
\hline Access to health facility & & & & \\
\hline With difficulty & 78.7 & 21.3 & 832 & $4.5, \mathrm{p}=0.01$ \\
\hline Without difficulty & 72.2 & 27.8 & 296 & \\
\hline Number of ANC visits in & & & & \\
\hline$<4$ & 78.1 & 21.9 & 836 & $3.51, p=0.035$ \\
\hline 4 or more & 72.5 & 27.5 & 292 & \\
\hline Husband's education leve & & & & \\
\hline Uneducated or primary & 73.3 & 26.7 & 131 & $10.27, p=0.006$ \\
\hline Secondary or tertiary & 77.3 & 22.7 & 651 & \\
\hline Unknown & 60.3 & 32.1 & 346 & \\
\hline Husband's number of chil & & & & \\
\hline Same as spouse & 70 & 30 & 210 & $3.75, p=0.289$ \\
\hline More than spouse & 74.4 & 25.6 & 366 & \\
\hline Fewer than spouse & 68.3 & 31.7 & 63 & \\
\hline Unknown & 75.7 & 24.3 & 589 & \\
\hline Total & 73.9 & 26.1 & 1128 & \\
\hline
\end{tabular}


Table 3. Binary logistic regression results showing Odds Ratio predicting uptake of contraception by women with disabilities in Uganda

\begin{tabular}{|c|c|c|c|c|}
\hline Predictor variables & OR & $\mathrm{CI}$ & OR & $\mathrm{CI}$ \\
\hline \multicolumn{5}{|c|}{ Access to health facilities } \\
\hline With difficulty ${ }^{\circledR}$ & 1 & & 1 & \\
\hline Without difficulty & $1.35^{*}$ & $1.03-1.95$ & $1.41 *$ & $1.02-1.89$ \\
\hline \multicolumn{5}{|c|}{ Received family planning messages on radio } \\
\hline $\mathrm{No}{ }^{\circledR}$ & 1 & & 1 & \\
\hline Yes & $1.87 * * * *$ & $1.35-2.58$ & $1.48^{*}$ & $1.04-2.11$ \\
\hline \multicolumn{5}{|c|}{ Number of surviving children } \\
\hline$<4$ & 1.02 & $0.78-1.34$ & 0.84 & $0.58-1.21$ \\
\hline $4+\AA$ & 1 & & 1 & \\
\hline \multicolumn{5}{|l|}{ Age groups } \\
\hline$<25$ ® & & & 1 & \\
\hline $25-24$ & & & $1.65 * *$ & $1.19-2.48$ \\
\hline $35+$ & & & 1.17 & $0.77-1.79$ \\
\hline \multicolumn{5}{|l|}{ Region } \\
\hline Kampala & & & $1.44 *$ & $1.12-2.26$ \\
\hline Central & & & 1.24 & $0.85-1.95$ \\
\hline Eastern & & & 0.84 & $0.44-1.58$ \\
\hline Northern & & & 1.3 & $0.80-2.11$ \\
\hline Western ${ }^{\circledR}$ & & & 1 & \\
\hline \multicolumn{5}{|l|}{ Level of education } \\
\hline Uneducated $\AA$ & & & 1 & \\
\hline Primary & & & $2.02 * *$ & $1.25-3.28$ \\
\hline Secondary & & & $2.49 * * *$ & $1.38-4.50$ \\
\hline Tertiary & & & $2.68 * * *$ & $1.22-5.90$ \\
\hline \multicolumn{5}{|l|}{ Wealth status } \\
\hline Poorer $\AA$ & & & 1 & \\
\hline Middle & & & $1.79 * * *$ & $1.18-2.72$ \\
\hline Richer & & & $2.01 * * * *$ & 1.353 .03 \\
\hline \multicolumn{5}{|l|}{ Access to the radio } \\
\hline Occasional ${ }^{\circledR}$ & & & 1 & \\
\hline Almost daily & & & $1.58^{*}$ & $1.05-1.64$ \\
\hline \multicolumn{5}{|c|}{ Number of ANC visits during last pregnancy } \\
\hline$<4 \mathbb{R}$ & & & 1 & \\
\hline $4+$ & & & $1.36^{*}$ & $1.09-1.91$ \\
\hline
\end{tabular}

The majority $(56 \%)$ of the women did not want another child, suggesting that they have already attained their desired family size. On the other hand, 4 in 10 wanted another child which suggests that they have not attained their desired family size. The women were predominantly rural, having primary education, were Christian and currently married. The regional distribution shows that most of the women (26.2 and 26.4\%) were from Eastern and Western regions followed by Central, Northern and Kampala regions. Table 1 also shows that nearly two-fifths of the women were in the poorer and richer wealth index groups; $56.7 \%$ had daily access to the radio; and 7 in 10 had ever received family planning messages on radio. However, 7 in 10 have difficulty accessing health facilities, attended less than 4 ANC visits during the most recent pregnancy and have never used a modern contraceptive method. Nearly 6 in 10 and 3 in 10 of the women have husbands with primary and secondary education respectively; and more than half of the women did not know the husbands' desired number of children.
Figure 1 presents women by the type of disability. Walking disability was by far the most common form of disability reported by $37.5 \%$, followed by memory loss, reported by nearly $27 \%$ of the women. Other important forms of disability were hearing (19\%) and sight (15.6\%) impairments. Inability to communicate was the least reported disability by about $1 \%$ of the women.

Table 2 presents differentials in uptake of contraception. The table shows that uptake of contraception was significantly more prevalent among women in the 25-34 year age group; in urban areas; increased monotonically with the level of education and wealth index group; and in Kampala and Central regions, followed by Eastern and Northern regions. More women having almost daily access to the radio had ever used contraceptives and nearly 3 in 10 of the women who received family planning messages through the radio also used contraceptives. Additionally, more than onequarter of the women accessing health facilities without difficulty and attended 4 or more ANC visits during the most recent pregnancy had ever used contraceptives. 


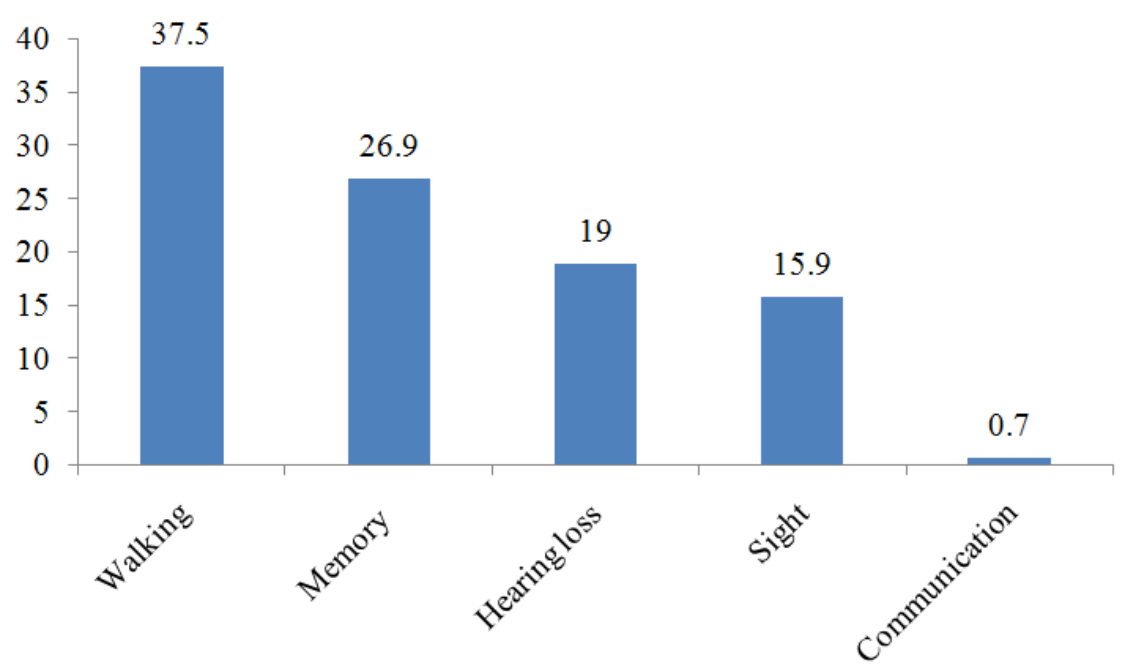

Fig. 1. Distribution of women by forms of disability

Regarding differentials in uptake of contraception by husband's characteristics, 26.7 and $32.1 \%$ of the women with husbands having secondary or tertiary education and unknown level of education respectively, had ever used contraceptives. Fertility intentions, religious affiliation, marital status, number of surviving children and husband's number of children desired were not significantly associated with uptake of contraception by women with disabilities in Uganda.

In Table 3 the result of the logistic regression model showing significant predictors of uptake of contraception is presented. Model 1 shows that the hypotheses predicting the effects of accessing health facilities without difficulty and receiving family planning messages on radio on uptake of contraception were confirmed. Uptake of contraception was significantly higher by $35 \%(\mathrm{CI}=1.03-1.95)$ and $87 \%(\mathrm{CI}=1.35$ 2.58) among women who accessed health facilities without difficulty and received family planning messages on the radio respectively. However, the number of surviving children was not a significant predictor of uptake of contraception.

Model 2 shows that accessing health facilities without difficulty significantly increased uptake of contraception by $6 \%$ to $1.41(\mathrm{CI}=1.02-1.89)$ times. On the other hand, receiving family planning messages on the radio attenuated uptake of contraception by $38 \%$ to $1.48(\mathrm{CI}=1.04-2.11)$ times but remained a significant predictor of contraception after controlling for other covariates. However, having 4 or more surviving children attenuated uptake of contraception by $18 \%$ to $0.84(0.58-1.21)$ but remained an insignificant predictor of contraception. Among the control variables, belonging to the 25-34 year age group $(\mathrm{OR}=1.65, \mathrm{CI}=1.19-2.48)$; residing in Kampala region $(\mathrm{OR}=1.44, \mathrm{CI}=1.12-2.26)$; and having primary $(\mathrm{OR}=2.02, \mathrm{CI}=1.25-3.28)$, secondary $(\mathrm{OR}=2.49, \mathrm{CI}=1.38-4.50)$ and tertiary education $(\mathrm{OR}=2.568, \mathrm{CI}=1.22-5.90)$ were significant predictors of uptake of contraception. Belonging to the middle $1.79(\mathrm{CI}=1.18-2.72)$ and richer $2.01(\mathrm{CI}=1.35$ $3.03)$ wealth index groups; having almost daily access to the radio $(\mathrm{OR}=1.58, \mathrm{CI}=1.05-1.64)$; and attending 4 or more ANC visits $(\mathrm{OR}=1.36, \mathrm{CI}=1.09-1.91)$ also significantly increased uptake of contraception.

\section{Discussion}

The health and socioeconomic benefits of contraception are greater for population groups at higher risk of socioeconomic and health vulnerability, which include women with disabilities. The objectives of the study were to estimate the prevalence and identify the significant predictors of uptake of contraception by women with disabilities. The study found that the mean number of children ever born was 4.2 and over 8 in 10 of the women were ever married which suggest that women with disabilities in Uganda are sexually active, desire to bear children and have similar marriage and fertility experiences as women without disabilities. The study also found that only $26 \%$ of women with disabilities had ever used a modern method of contraception which is low; only 3 in 10 of the women who received family planning messages on radio; nearly $28 \%$ of the women who accessed health facilities without difficulty; and only one-quarter of the women having 4 or more surviving children had ever used a modern method of contraception. The above finding raises the importance of addressing the challenges women with disabilities face in using sexual and reproductive health services, including uptake of contraception. 
The study found that the prevalence of contraception among women with disabilities is similar to the prevalence of contraception among ever married women in Uganda (UBOS and ICF Inc, 2012). The finding suggests that women with disabilities experience similar socio-cultural and structural barriers in using contraceptives as women without disabilities in Uganda. These challenges include lack of or poor access to appropriate contraceptive method of choice, fear of side effects, community norms regarding family size, partner disapproval and poor attitude of health workers (FHI 360, 2014; Kayongo, 2014). Other previous studies elsewhere also found that poor access to health facilities and attitudes of health workers towards women with disabilities impede their access to family planning services (Andersona and Kitchinb, 2000; Hamid and Stephenson, 2006). In these regards, increasing access to health facilities and changing the attitudes of health workers in providing services by inclusion of disability training, effective and supportive supervision are required. Adapting community-based outreach family planning services which can be implemented by Community Health Workers now available in Uganda could also increase access to contraception for hard-toreach women as well as hard-to-reach areas. Because contraception is usually the least of the services that take women to health facilities, hard-to-reach women in rural areas are most likely to miss out on contraception. In addition, the community-based distribution of family planning services can enable women with disabilities to avoid the stigma associated with public uptake of contraception, which has been successful in similar family planning programmes in some parts of India and Pakistan (Servais, 2006).

Our study found that despite the low prevalence of contraceptive uptake by women with disabilities, access to health facilities without difficulty increased uptake of contraception by women with disabilities. This could be attributed to the increased expansion of the basic health care services facilities by reducing the distance and time taken to reach facilities, increased range of services at facilities including family planning services now provided by $83 \%$ of health facilities and the relatively low cost of outpatient services in Uganda (IHME, 2014). However, access to health facilities in rural areas may impede uptake of contraception for women with disabilities because of higher transport costs, poor road network and limited means of transport which could contribute to the lower prevalence of contraception by women with disabilities, which is consistent with a similar study elsewhere (Ganle et al., 2016).

The study also confirmed the hypothesis that receiving family planning messages on radio significantly increased uptake of contraception and persisted even after being controlled for by other demographic and social characteristics of the women. The finding compares well with the high radio coverage estimated at nearly $70 \%$ of the general population and consistent with reports on radio coverage in Uganda (UBOS, 2016). The increased uptake of contraception observed in this study is consistent with a previous study in the general population in Kenya (Westoff and Rodriguez, 1995) which found that the radio alone contributed to uptake of contraception by $26 \%$ among women who received family planning messages on the radio compared to women who did not. A similar study in Nigeria found that apart from messages on television, the radio was a very important predictor of uptake of contraception (Ajaero et al., 2016) which suggests that messages on the benefits of smaller family size, methods of achieving small family size and where to obtain such methods can change attitudes and have a positive effect on uptake of contraception even among women in difficult circumstances such as those with disabilities.

Our finding shows that women with disability who attended ANC 4 or more times were more likely to have used contraception. The finding is consistent with previous studies in the general population of women in Kenya (Singh et al., 2009) and Mexico (Tisha et al., 2015) which found that women who received ANC regularly also received contraception services which was attributed to the contraception counselling women received during ANC. Many women do not take up contraception because they have either not attended antenatal care or do not usually return for contraceptive counseling after birth. As a result, providing contraception counselling during ANC could be the most effective timing to encourage new mothers to take up contraception and prevent unintended pregnancies.

Our study found that women with disabilities in Kampala metropolitan region were significantly more likely to have used contraception than women from other regions. This finding is consistent with previous studies on contraception in Uganda, which found that women in urban areas have a higher uptake of contraception (Vernon, 2009) which was attributed to better knowledge, better access to and adequate supply of contraceptive commodities in large urban areas such as Kampala region than in rural regions such as Karamoja region (Paul et al., 2015). Another study, also in Uganda, found significant regional variation in uptake of contraception, with the northern and Karamoja regions, which have the lowest levels of all development indices, having the lowest contraceptive prevalence. The study suggests that contraception is highly influenced by other development indicators such as level of education and income (Andi et al., 2014). From these studies, we can conclude that the regional variation in uptake of contraception is not necessarily a problem of disability, but rather the manifestation of structural inequalities. 
Addressing these inequalities will not only increase uptake of contraception by women with disabilities, but by all women in Uganda.

Furthermore, the study found that uptake of contraception by women with disability increased with the level of education. Having primary, secondary or higher education were significant predictors of uptake of contraception by women with disabilities. This finding is consistent with the findings in the general population of women in other studies elsewhere (Apanga and Adam, 2015; Asiimwe et al., 2013) and in Uganda (Kiragu and Zabin, 1995). These studies have identified education as an important structural factor that increases the selfefficacy of individuals regardless of their life situations. The self-efficacy created by education empowers women to use reproductive health services including contraception by overcoming systemic barriers such large family size norms and subservience to men on matters related to sexuality. Education also increases uptake of contraception by eradicating myths associated with the side-effects, safety and long-term effects on fertility that are perceived to result from using contraceptives (Bbaale and Mpuga, 2011). Improving the access of women with disabilities to education can increase their self-esteem and enable them to demand and obtain contraceptive services.

We also found that wealth status is a significant predictor of uptake of contraception even among women with disabilities, showing that uptake of contraception increased with wealth status which is in agreement with previous studies including one in Uganda (Chipeta et al., 2010; George, 2002). The lower uptake of contraception among poor women is attributed to inequalities exacerbated by differences in wealth status, which also occurs among women with disabilities. Additionally, women with disabilities in the middle and richer wealth quintile groups can assert their choice and timing of contraception independent of their husbands, which women in the poorer wealth quintile may find difficult to do as they depend on their husbands for the resources they need to access services.

Our study found that access to the radio on an almost daily basis increased uptake of contraception by women with disabilities. The finding is consistent with the general belief that the radio, as the most available channel of information in poor societies, is the most effective channel of transmitting communications about behaviour change to marginalized and vulnerable populations. A previous report found that the radio can be an effective channel for breaking down cultural barriers on reproductive health issues (Kibira et al., 2014). In Nigeria, the extensive use of the media, particularly the radio, to transmit family planning information appears to have increased uptake of contraception (Nwadigwe, 2013). However, it should be noted that the easy access to the radio by most poor households does not mean automatic access to information about reproductive health behaviour change. Many households in sub-Saharan Africa own radio sets, but the radio is often not used effectively for accessing health-promoting information. This reality was observed in a study in Kenya where the radio was mostly used as a channel of entertainment (Akpobo, 2015). Nevertheless, strategically placed announcements and information on family planning can be made to reach potential users, which could explain the increased uptake of contraception by women with disabilities who have almost daily access to the radio.

\section{Limitations}

Although our study was able to show the important factors predicting increased uptake of contraception by women with disabilities, the results could have been affected by some limitations. These include the selfreported data which may have been affected by social desirability bias; and the knowledge by the women that disability is sometimes negatively construed which could have influenced reporting based on what they perceived to be happening rather than what they actually did. Additionally, the use of cross-sectional data does not explain the temporal nature of contraception behaviour as this may change overtime. In order to fully understand contraceptive behavior of women with disabilities, we recommend a qualitative study that can unpack and identify deeper insights behind the quantitative results we have observed so far. Nevertheless, the present study contributes to our understanding of uptake of contraception by women with disabilities, which is of importance to public health. We were able to identify some significant variables that increase uptake of contraception, which could help in the development of interventions to address the unmet need for contraception by women with disabilities.

\section{Conclusion}

The result of this study shows that the Anderson Behavioural Model on Health Service Use is appropriate in explaining uptake of contraception by women with disabilities. As in the general population, the present study revealed a high unmet need for contraception among women in Uganda with disabilities. The results also shows that access to health facilities and access to family planning messages on the radio are imperatives in increasing uptake of contraception by women with disabilities. This is because disabilities of any kind could impede effective use of health facilities if persons with disabilities struggle to reach health facilities and or have no access to family planning messages. Additionally, removing structural barriers caused by differences between regions, levels of education, wealth index 
groups and access to family planning messages are important in increasing uptake of contraception by women with disabilities.

\section{Acknowledgement}

The authors thank the Uganda Bureau of Statistics for the data used in this study. We also extend our appreciation to the data collectors, research subjects and the reviewers for the comments and suggestions made to improve the manuscript.

\section{Author's Contributions}

NA and SK both contributed to conceptualization, analysis, interpretation of results and write up of the manuscript. We also contributed critically in addressing the comments made by reviewers and revision of the manuscript for publication.

\section{Disclosure of Interests}

The authors have no interest to disclose in this study.

\section{References}

Ahumuza, S.E., J.K. Matovu, J.B. Ddamulira and F.K. Muhanguzi, 2014. Challenges in accessing sexual and reproductive health services by people with physical disabilities in Kampala, Uganda. Reprod. Health, 11: 59-59. DOI: 10.1186/1742-4755-11-59

Ajaero, C.K., C. Odimegwu, I.D. Ajaero and C.A. Nwachukwu, 2016. Access to mass media messages, and use of family planning in Nigeria: A spatiodemographic analysis from the 2013 DHS. BMC Public Health, 16: 427-427. DOI: $10.1186 / \mathrm{s} 12889-016-2979-\mathrm{z}$

Akpobo, O., 2015. Mass media health communication: Imperative for sustainable health development in Nigeria. Mgbakoigba J. Afr. Stud., 4: 1-6.

Andersona, P. and R. Kitchinb, 2000. Disability, space and sexuality: Access to family planning services ${ }^{1}$. Soc. Sci. Med., 51: 1173-1173. DOI: $10.1016 / \mathrm{S} 0277-9536(00) 00019-8$

Andi, J.R., R. Wamala, B. Ocaya and A. Kabagenyi, 2014. Modern contraceptive use among women in Uganda: An analysis of trend and patterns (19952011). Etude Popul. Afr. Popul. Stud., 28: 1009-1021. DOI: $10.11564 / 28-0-553$

Apanga, P.A. and M.A. Adam, 2015. Factors influencing the uptake of family planning services in the Talensi District, Ghana. Pan Afr. Med. J. DOI: 10.11604/pamj.2015.20.10.5301

Asiimwe, J., P. Ndugga and J. Mushomi, 2013. Sociodemographic factors associated with contraceptive use among young women in comparision with older women in Uganda. United States Agency for International Development.
Babitsch, B., D. Gohl and T. von Lengerke, 2012. Rerevisiting andersen's behavioral model of health services Use: A systematic review of studies from 1998-2011. GMS Psychosoc. Med. PMID: 23133505

Barriga, S.R. and S.R. Kwon, 2010. As if we weren't Human: Discrimination and violence against women with disabilities in northern Uganda. Human Rights Watch.

Bbaale, E. and P. Mpuga, 2011. Female education, contraceptive use and fertility: Evidence from Uganda. J. Sustainable Develop., 6: 20-47. DOI: 10.7916/D80P0ZPG

Cates Jr, W., 2010. Family planning: The essential link to achieving all eight millennium development goals. Contraception, 81: 460-461. DOI: $10.1016 /$ j.contraception.2010.01.002

Chakravarti, U., 2008. Burden of caring families of the disabled in Urban India. Ind. J. Gend. Stud., 15: 341-363. DOI: 10.1177/097152150801500207

Charlton, J., 2000. Nothing about us without us: Disability oppression and empowerment. University of Califonia Press.

Chipeta, E.K., W. Chimwaza and L. Kalilani-Phiri, 2010. Contraceptive knowledge, beliefs and attitudes in rural Malawi: Misinformation, misbeliefs and misperceptions. Malawi Med. J. DOI: $10.4314 / \mathrm{mmj} . v 22 \mathrm{i} 2.58790$

Eisland, N., 1994. The Disabled God: Toward a Liberatory Theology of Disability. 1st Edn., Abingdon Press, Nashville, ISBN-10: 0687108012, pp: 139.

Elisa, T. and J. Wang, 2003. Statistical Methods for Survival Data Analysis. 3rd Edn., John Wiley and Sons, New York, ISBN-10: 0471458554, pp: 534.

FHI 360, 2014. Contextual barriers and coping strategies for uptake of modern contraceptive services and commodities in a selected community in Uganda.

Galati, A.J., 2015. Onward to 2030: Sexual and Reproductive Health and Rights in the Context of the Sustainable Development Goals. Guttmacher Policy Rev.

Ganle, J.K., E. Otupiri, B. Obeng, A.K. Edusie and A. Ankomah et al., 2016. Challenges Women with Disability Face in Accessing and Using Maternal Healthcare Services in Ghana: A Qualitative Study. PloS One, 11: e0158361-e0158361.

DOI: 10.1371/journal.pone.0158361

George, 2002. Nursing Theories: The Base For Professional Nursing Practice. 5th Edn., Prentice Hall, Upper Saddle River, N.J., ISBN-10: 0838571107, pp: 611.

Hamid, S. and R. Stephenson, 2006. Provider and health facility influences on contraceptive adoption in urban Pakistan. Int. Fam. Plan. Perspect., 32: 71-78. DOI: $10.1363 / 3207106$ 
Haq, S.M.A., T. Vanwing and L. Hens, 2010. Perception, environmental degradation and family size preference: A context of developing countries. J. Sustain. Dev., 3: 102-108.

DOI: $10.5539 /$ jsd.v3n4p102

IHME, 2014. Health service provision in Uganda: Assessing facility capacity, costs of care and patient perspectives. Institute for Health Metrics and Evaluation.

Kaplan, C., 2006. Special issues in contraception: Caring for women with disabilities. J. Midwifery Women's Health, 51: 450-456.

DOI: $10.1016 /$ j.jmwh.2006.07.009

Kayongo, S.B., 2014. Uptake of modern contraception among youths $(15-24)$ at community level in busia district, Uganda. Makerere University.

Kibira, S.P., P. Ndugga, E. Nansubuga, A. Sewannonda and B. Kwagala et al., 2014. Contraceptive uptake among married women in Uganda: Does empowerment matter? Etude Popul. Afr., 28: 968-968. DOI: $10.11564 / 28-0-572$

Kiragu, K. and L.S. Zabin, 1995. Contraceptive use among high school students in Kenya. Int. Fam. Plan. Perspect., 21: 108-113. DOI: 10.2307/2133184

Lang, R., 2009. The United Nations Convention on the right and dignities for persons with disability: A panacea for ending disability discrimination? ALTER-Eur. J. Disabil. Res. Eur. Rech., 3: 266-285. DOI: 10.1016/j.alter.2009.04.001

Leigh, I.W., L. Powers, C. Vash and R. Nettles, 2004. Survey of psychological services to clients with disabilities: The need for awareness. Rehabil. Psychol., 49: 48-54. DOI: 10.1037/0090-5550.49.1.48

Low, H. and L. Pistaferri, 2010. Disability risk, disability insurance and life cycle behavior. National Bureau Econom. Res. DOI: 10.3386/w15962

Lwanga-Ntale, C., 2003. Chronic poverty and disability in Uganda.

Mitra, S., A. Posarac and B. Vick, 2013. Disability and poverty in developing countries: A multidimensional study. World Dev., 41: 1-18. DOI: 10.1016/j.worlddev.2012.05.024

Naami, A., 2015. Disability, gender and employment relationships in Africa: The case of Ghana. Afr. J. Disabil., 4: 11-11. DOI: 10.4102/ajod.v4i1.95

Nwadigwe, C.E., 2013. Theatre for development: An alternative programme for reproductive health communication in urban Nigeria. Afr. Sociol. Rev. Afr. Sociol., 16: 102-118.
Paul, B., A.S. Ayo and N. Ayiga, 2015. Rural-urban contraceptive use in Uganda: Evidence from UDHS 2011. J. Hum. Ecol., 52: 168-182.

Richard, B.O., 2014. Families, well-being and inclusion: Rethinking priorities for children with cognitive disabilities in Ladakh, India. Childhood, 21: 308-323. DOI: $10.1177 / 0907568214526264$

Servais, L., 2006. Sexual health care in persons with intellectual disabilities. Ment. Retard. Dev. Disabil. Res. Rev., 12: 48-56. DOI: 10.1002/mrdd.20093

Singh, S., J. Deborroch, L. Ashford and M. Vlassoff, 2009. Adding it up: the Costs and benefits of investing in family planning and maternal and newborn health.

Thomas, C., 2004. How is disability understood? An examination of sociological approaches. Disabil. Soc., 19: 569-583.

DOI: $10.1080 / 0968759042000252506$

Tisha, S., S.R. Haque and M. Tabassum, 2015. Antenatal care, an expediter for postpartum modern contraceptive use. Res. Obstet. Gynecol., 3: 22-31. DOI: $10.5923 /$ j.rog.20150302.03

Trani, J.F., J. Browne, M. Kett, O. Bah and T. Morlai et al., 2011. Access to health care, reproductive health and disability: A large scale survey in Sierra Leone. Soc. Sci. Med., 73: 1477-1489. PMID: 22014873

Tuomilehto, J. and N. Wareham, 2002. The definition of disability: What is in a name? N Engl. J. Med., 346: 393-403.

UBOS and ICF Inc, 2012. Uganda Demographic and Health Survey 2011. Kampala, Uganda, UBOS and Calverton, Maryland: ICF International Inc.

UBOS, 2016. National Population and Housing Census 2014: Main report.

Ujoh, F., 2014. Population growth and land resource conflicts in Tivland, Nigeria. Resour. Environ., 4: 67-78.

Vernon, R., 2009. Meeting the family planning needs of postpartum women. Stud. Fam. Plann., 40: 235-245. DOI: $10.1111 /$ j.1728-4465.2009.00206.x

Westoff, C.F. and G. Rodriguez, 1995. The mass media and family planning in Kenya. Int. Fam. Plan. Perspect., 21: 26-36. DOI: 10.2307/2133602

WHO, 2011. World Report on disability. World Health Organization, Geneva, Switzerland 